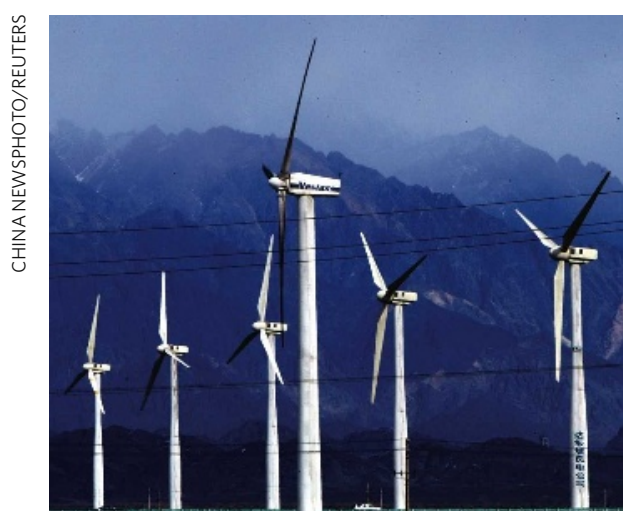

China aims to expand the number of wind turbines.

\section{China declares ambitious alternative-energy plans}

Renewable energy will contribute $10 \%$ of China's energy consumption by 2010 , forecasts the country's latest 5-year plan. This ambitious target, equivalent to the energy produced from burning $\mathbf{3 0 0}$ million tonnes of coal, was announced by the country's National Development and Reform Commission last week.

The scheme will promote the development and commercialization of biofuels, wind power, solar energy, hydropower and natural gas. Economic incentives, such as funding and tax relief, will be offered to companies, and taxation, concessions and price regulation will be used to provide guarantees for the market.

China hopes that the policies will help it to meet its targets of reducing the amount spent on energy per unit of gross domestic product by $20 \%$ and of major pollutant discharge by $10 \%$ from 2005 levels between 2006 and 2010. At the end of the first year, the country was already behind its target.

Separately, energy officials announced that they would scale up construction of nuclear power plants to get at least $5 \%$ of the country's energy needs from nuclear sources by 2020 . Overall, nuclear power and renewable energy are set to contribute at least half of China's energy mix by 2050.

\section{Faculty protest at sale of Canadian observatory}

The University of Toronto's David Dunlap Observatory, which houses a 1.88-metre reflecting telescope in the town of Richmond Hill, Ontario, may see last light as soon as 30 June. The university is negotiating the sale of the observatory and 77 hectares of surrounding land, estimated to be worth Can $\$ 100$ million (US\$98 million).

Proceeds of the sale will fund a new astronomy and astrophysics institute.
But Tom Bolton, one of two members of the university's faculty who still use the telescope regularly, argues that it should be kept for educational purposes at least.

\section{Joint drug venture to end after 30 years}

Drug firms Takeda of Osaka, Japan, and Abbott Laboratories of Chicago, Illinois, are splitting up a joint venture begun in 1977.

Takeda, which may pay Abbott US $\$ 1.5$ billion for the split, is expected to retain the heartburn drug Prevacid (lansoprazole), with Abbott taking the cancer drug Lupron (leuprolide). Both drugs had been produced through the joint venture TAP Pharmaceutical Products, based in Lake Forest, Illinois. Together, the two drugs accounted for around $\$ 3$ billion in sales last year.

Outstanding mentors in Germany

This week sees the launch of the 2008 Nature Awards for Mentorship in Science. This year the competition will be held in Germany. Readers wishing to nominate outstanding mentors working in Germany should go to: www.nature. com/nature/mentoringawards/germany. The deadline for nominations is 4 July. The winners, who each receive a cash prize of $€ 10,000$ (US\$15,450), will be announced in October. 